\title{
Das Staunen über Vergils Dichtkunst: Marco Girolamo Vida
}

\author{
Ecco Alessandro, il mio signor, Farnese: \\ oh dotta compagnia che seco mena! \\ Fedro, Capella, Porzio, il bolognese \\ Filippo, il Volterano, il Madalena, \\ Blosio, Pierio, il Vida cremonese, \\ d'alta facondia inessicabil vena, \\ e Lascari e Mussoro e Navagero, \\ e Andrea Marone e 'l monaco Severo. ${ }^{1}$ (Orlando Furioso, XLVI, 13)
}

\subsection{Historische Notizen und Rezeptionsgeschichte}

Das Lehrgedicht De arte poetica von Marco Girolamo Vida erschien 1527 in autorisierter Form. ${ }^{2}$ Es entstand während Vidas Zeit an der Kurie in Rom (15101534) und stellt einen wesentlichen Bestandteil des « umanesimo cortigiano ${ }^{3}$ im Schatten der wirkungsmächtigen Päpste Julius II., Leo X. und Clemens VII. dar. ${ }^{4}$ De arte poetica wurde höchstwahrscheinlich im Zeitraum zwischen 1515 und $15^{20}$ verfasst, ${ }^{5}$ gemeinsam mit weiteren literarischen Werken (Lehrgedichte, Hymnen, Oden, Eklogen, Briefe), die Vida noch vor seinem

1 Ariost, Der rasende Roland, übertragen von Johann Diederich, Bd. 2, München 1980, S. 585: «Sieh Alexander, meinen Herrn, Farnese. / Und sein Geleit, gelehrt und ruhmeshell: / Fedro, Porzio, Philipp der Bolognese, / und Maddaleni, Volterran, Capell; / und Blosio, Pierio und der Cremonese / Vida, der Dichtkunst unversiegter Quell; / und Lascaris, Musurr und Navagero, / Andreas Maro und der Mönch Severo.»

2 Susanne Rolfes, Die lateinische Poetik des Marco Girolamo Vida und ihre Rezeption bei Julius Caesar Scaliger, München / Leipzig 2001, S. 17. Der gesamte biographische Überblick ist überaus lesenswert (S. 15-29).

3 Raffaele Girardi, Introduzione, in: Marco Girolamo Vida, L'arte poetica, introduzione, testo, traduzione e note a cura d Raffaele Girardi, Bari 1982, S. 10.

4 Die drei Päpste sind als Repräsentanten der Renaissance in die Geschichte eingegangen: Julius II. (Giuliano della Rovere), Leo X. (Giovanni de' Medici) und Clemens VII. (Giulio de' Medici). Siehe Rolfes, Die lateinische Poetik, S. 17 .

5 Gregor Vogt-Spira, Von Auctoritas zu Methode. Vergil als literarisches Paradigma in der Poetik des M. G. Vida, in: Ecker / Zintzen, Saeculum tamquam aureum, S. 152. 
Hauptwerk - dem christlichen Epos Christias $^{6}$ - internationalen Ruhm einbringen sollten.

De arte poetica zählt mit Giovanni Pontanos Actius und Bartolomeo Della Fontes De poetice $(1491)^{7}$ zu den ersten poetologischen Texten der Renaissance und kann aufgrund seiner weiten Verbreitung als zentraler Beitrag zur Literatur(-theorie) des frühen Cinquecento gewertet werden. Vom Cinquebis zum Settecento sind 98 Ausgaben dokumentiert, 44 davon erschienen im 16. Jahrhundert. Mehr als zwanzig Übersetzungen ins Italienische, Englische, Französische, Deutsche, Polnische, Portugiesische, Spanische und Ungarische sind belegt. ${ }^{8}$ Der Erfolg von De arte poetica bildete den Grundstein einer umfangreichen europäischen Produktion poetologischer Texte $^{9}$ - insbesondere in Italien, etwas später auch in Frankreich und in England.

Vida wurde von vielen Zeitgenossen rezipiert: Einige - zum Beispiel Celio Calcagnini - lobten ihn als «Mann, der einzig zur Dichtung geboren ist» («vir unus ad poeticam natus»), andere - wie Erasmus von Rotterdam missbilligten ihn: «In Vida sehe ich nichts. » («Vidæ nihil vidi.») ${ }^{10}$ Ein einschneidendes Ereignis der Rezeptionsgeschichte ist sicherlich die ambivalente Einschätzung von Vidas Poetik in Scaligers Poetices libri septem. Denn obwohl Scaliger Vidas Talent und die Poetik lobt, bezeichnet er sie als « unnötig [...], weil sie darüber handelt, was schon besprochen worden ist ». ${ }^{11}$ Scaliger verweist explizit auf De arte poetica und setzt Vida auf Augenhöhe mit Aristoteles und Horaz. Andererseits sieht Scaliger sich als Vidas Korrektor und Verbesserer. De arte poetica wird damit die Rolle des unvollständigen Prototyps zugeschrieben, insbesondere weil die Poetik des Aristoteles noch nicht einbezogen wurde und der Text nur bedingt logisch-systematisch formuliert ist.

6 Marco Girolamo Vida, Christiad, translated by James Gardner, Cambridge Massachusetts / London 2009, U2: «It was by far the most popular Christian epic of the Renaissance, appearing in almost forty editions before 1600. »

Della Fontes Poetik orientiert sich in erster Linie an Horaz und hat - im Gegensatz zu Vidas De arte poetica - keine grosse Verbreitung erfahren. Della Fontes Text weicht kaum von den horazischen Thesen ab, wohingegen Vida seine Poetik trotz klassischer Quellen freier gestaltet. Siehe dazu Agniesz Ka Paulina Lew, Marcus Hieronymus Vida. Poeticorum libri tres, Frankfurt a. M. 2011, S. 104, Fn. 168.

8 Rolfes, Die lateinische Poetik, S. 3 o.

9 Rolfes, Die lateinische Poetik, S. 31.

10 Lew, Marcus Hieronymus Vida, S. 150-151. Das Zitat Calcagninis stammt aus CaELII CALCAGnini, De talorum ac tesserarum et calculorum ludis ex more veterum, in: Opera aliquot, Basileae 1544, S. 299. Das Zitat von Erasmus von Rotterdam stammt aus Opus epistolarum Desiderii Erasmi Roterodami, herausgegeben von H. M. Allen und H. W. Garrod, Bd. 10 (1532-1533), Oxonii 1941, Brief 2791, 48sqq, und Brief 2810, 57. Die Briefe sind online zu lesen auf www.archive.org. 
Nicht nur, aber auch bedingt durch die Beanspruchung durch Scaliger erlangte Vida beträchtlichen Ruhm als Vorgänger der Klassizisten. Autoren wie Boileau oder Pope bauen auf Vida auf, um ihre Theorien der Harmonie und der Einheit zu konzipieren. ${ }^{12}$ Pope hat Vida in seinem Essay on Criticism wörtlich zitiert und ihn gemeinsam mit Leo X. und Raffael als eine der grossen Figuren der italienischen Renaissance genannt:
A Raphael painted, and a Vida sung. Immortal Vida! on whose honour'd brow The poet's bays and critic's ivy grow: Cremona now shall ever boast thy name, As next in place to Mantua, next in fame! $!^{13}$

Nach Pope reihte auch Charles Batteux De arte poetica im Jahr 1771 in den Kanon der grossen Poetiken ein - neben Aristoteles, Horaz und Boileau. ${ }^{14}$ Erst im 19. Jahrhundert setzte im Zuge romantischer Bewegungen ${ }^{15}$ eine immer stärkere Abwertung ein, die zwar im preussischen Pastor Johann David Müller ${ }^{16}$ noch eine zwischenzeitliche Abkehr fand, im 2o. Jahrhundert dann aber durch George Saintsbury ihren Höhepunkt erreichte. Saintsbury bezeichnet Vida nicht nur als Begründer der «critical orthodoxy of the sixteenth, seventeenth, and eighteenth [century]» sowie als «Vergil-worship which reigned throughout the Neo-Classical dispensation », sondern De arte poetica auch als "poorest and most beggarly» Poetik überhaupt. ${ }^{17}$ Insbesondere letzteres Urteil verkennt, inwiefern Vida mit De arte poetica die klassischen Ideale im Rahmen seiner Forderungen nach Originalität und Innovation auf eine kreative Art und Weise erweitert hat. Es wird sich zeigen, dass die Frage

12 Lecointe, Lidéal et la différence, S. 483; ebenso Gardner, Introduction, in: Vida, Christiad, S. IX.

13 Alexander Pope, Essay on Criticism, Bd. 3, Vv. 704-708, in: Ders., The Works of Alexander Pope, with his last corrections, additions and improvements; together with all his notes, Bd. 1, Edinburgh 1767, S. 104. Zitiert aus: LeW, Marcus Hieronymus Vida, S. $15^{2}$.

14 Vogt-SPira, Von Auctoritas zu Methode, S. 151.

15 PAPPE, Introduction, in: VIDA, De arte poetica, S. 7.

16 Jesus Christus. Ein lateinisches Heldengedicht des Erzbischofs gesungen von Johann David Müller, Hamburg 1811, S. XVII-XVIII: «Vida's Poetik, ein Werk, das seinen Meister lobt und es sattsam beweist: dass ihm sein vortreffliches Genie und seine lange Uebung die Lehren zu einem guten schriftlichen Vortrag überhaupt und zur dichterischen Behandlung eines Gegenstandes insbesondere diktirten, in fast jedem Gymnasium bekannt, und so ist auch sein Schachspiel seit etlichen Jahren nach Würden geschätzt worden; nur seine Christias blieb im Dunkel, sein größtes Werk! » Zitiert aus LEW, Marcus Hieronymus Vida, S. 155.

17 Lew, Marcus Hieronymus Vida, S. 153-158. Saintsburys Zitate stammen aus George SAINTSBuRY, A History of Criticism and Literary Taste in Europe, Bd. 2, Edinburgh/London 1928, S. 29-30, 34 (gesamte Kritik S. 29-37). 
nach dem Staunen ausgesprochen gut dazu geeignet ist, ebendiese Originalität wieder aufzudecken. ${ }^{18}$

\subsection{De arte poetica}

De arte poetica ist, obwohl ausschliesslich poetologischen Inhalts, in erster Linie ein poetisches Werk und kein Traktat. Verfasst in daktylischen Hexametern ${ }^{19}$ ist das Werk unter anderem der Silva Nutricia Polizianos verwandt, dies insbesondere aufgrund der mythologischen Begründung der Dichtung und der bewundernden Haltung gegenüber der antiken Poesie. ${ }^{20}$

Le seul discours digne de la poésie est un chant de louange qui la répète: L'art poétique entre donc lui-même dans la catégorie du genre épidictique laudatif et de la poésie. [...] La forme de l'art poétique s'adapte ainsi à l'objet merveilleux dont elle traite, à la poésie. ${ }^{21}$

Vielfältige Aspekte der Dichtung werden behandelt: Tradition, Imitation, Inspiration, Geschichts- und Politikbezug, Enkomiastik, Epos und epischer Stil, Rhetorik sowie das Verhältnis von Schüler und Lehrer. Ebenfalls werden die Themen der Glaubwürdigkeit und der Wahrscheinlichkeit - zentral für die klassizistischen Poetiken - aufgegriffen. Laut Jean Pappe, dem jüngsten Herausgeber und Übersetzer von Vidas De arte poetica, repräsentiert das Werk den typisch humanistischen Versuch, gegenläufige Tendenzen zu versöhnen:

[...] comment donner leur juste part à l'inspiration et au travail artistique? comment s'appuyer sur les auteurs anciens pour manifester son originalité par la pratique d'une imitation créatrice? comment satisfaire à un double souci de fantaisie et de rigueur, de concision et d'exubérance, de grandeur et de simplicité? ${ }^{22}$

18 Heute wird Vida nur noch hie und da von einer kleinen Gruppe von Spezialisten gelesen und studiert. Das zeigt unter anderem, « wie sehr diese Dichtungslehre an die spezifischen Bedingungen der frühen Neuzeit gebunden ist». Siehe Vogt-Spira, Von Auctoritas zu Methode, S. 151.

19 Vgl. I, Vv. 33-38.

20 Pappe, Introduction, S. 10. Denizot, „Comme un souci“, S. 65: «Toute sa poétique est fondée sur l'admiration qu'il éprouve lui-même devant les œuvres du passé [...] »

21 Denizot, „Comme un souci“, S. 68-69.

22 PAPPE, Introduction, S. 8. 
Es lassen sich Bezüge zu den Rhetorikern Cicero ${ }^{23}$ und Quintilian sowie vereinzelt auch zur Poetik des Horaz ausmachen. ${ }^{24}$ Insbesondere die Institutiones oratoriae vereinen eine Vielzahl von Inhalten, die auch in De arte poetica bedeutsam sind: den pädagogischen Gestus, die Bewunderung der antiken Autoren, die mythologischen Motive, den Fokus auf stilistische Regeln sowie die Reflexion über die Imitation und Inspiration des Poeten. ${ }^{25}$ Wie Quintilian versucht Vida, seinen Schülern nicht ein sprödes und dogmatisches Regelwerk zu vermitteln, sondern sie anhand der anschaulichen Präsentation ausgewählter Mittel und intertextueller Verweise zur Dichtung zu ermutigen. ${ }^{26}$ Von Aristoteles scheint Vida nur die Rhetorik, nicht aber die Poetik gekannt zu haben - zumindest sind keine direkten Einflüsse erkennbar. ${ }^{27}$

De arte poetica gliedert sich in drei Bücher. Das erste Buch behandelt das Ziel und die Methode der literarischen Erziehung und Bildung, gepaart mit einer begeisterten Lobpreisung der Dichtung. Der Schüler wird über die Auswahl des richtigen Genres, die nachzuahmenden Modelle sowie die Geschichte der Dichtung, die in Vergil ihren Höhepunkt findet, unterrichtet. ${ }^{28}$ Das zweite Buch ist den Regeln der inventio und der dispositio gewidmet, während das dritte Buch Erläuterungen zur elocutio beinhaltet. ${ }^{29} \mathrm{Im}$ zweiten und im dritten

23 Explizit in I, Vv. 385-388.

24 Rolfes, Die lateinische Poetik, S. 77: «In der Forschung wird der Einfluss der horazischen Poetik auf Vida insgesamt überbetont. »

25 Rolfes, Die lateinische Poetik, S. 78, Fn. 338-340. Rolfes verweist insbesondere auf folgende Stellen der Inst. Orat.: VIII, pr. 21; 3, 71; 6, 4-6, 15, 17, 19, 67-76; IX, 1, 33; X, 1, 6.

26 Vgl. Inst. Orat., VIII, Prooemium. Siehe ebenfalls Denizot, „Comme un souci“, S. 68.

27 Rolfes, Die lateinische Poetik, S. 75-76. Es gibt Forscher - zum Beispiel Theresa Chevrolet -, die versucht haben, eine gewisse Nähe zwischen Aristoteles' und Vidas Poetik herzustellen, basierend auf dem Wunderbaren und Aussergewöhnlichen, das bei Aristoteles in Zusammenhang mit dem Epos genannt wird, sowie dem beiderorts zu findenden Verweis auf ein notwendiges Mass an Wahrscheinlichkeit und Glaubwürdigkeit des Dargestellten. Dazu ist zu sagen, dass Vida das Epos nicht im Rahmen der aristotelischen Genres konzipiert, sondern es neben der Bukolik und poetischen Lehrgedichten in der Nachfolge Vergils versteht - die beiden letzteren Genres werden von Aristoteles nicht erwähnt. Das „Aussergewöhnliche“ ist für Vida eine Charakteristik aller Dichtungen, er hebt es nicht speziell für das Epos hervor. In Bezug auf Wahrscheinlichkeit und Glaubwürdigkeit scheint Vida zudem eher von Quintilian inspiriert zu sein (vgl. Inst. Orat., IV, $3^{1}$ ff.). Andres als Aristoteles konzipiert Vida die Prinzipien von Wahrscheinlichkeit und Glaubwürdigkeit nicht in Bezug zur (erwünschten) Wirklichkeit, sondern ausschliesslich im innerliterarischen Bereich der Dichtung. Siehe dazu AGUzzIBarbagli, Humanism and Poetics, S. 127. Für Chevrolet siehe Chevrolet, Lidée de la fable, S. 533-537.

28 PAPPE, Introduction, S. 11.

29 WeInberg, A History, S. 715-719. 
Buch werden Mittel thematisiert, mit denen der Dichter spezifische Effekte auf den Leser ausüben, insbesondere dessen Aufmerksamkeit gewinnen kann:

Vida transpose à la narration épique les problèmes qu'un orateur rencontre et les moyens qu'il doit mettre en œuvre dans un plaidoirie: objectifs du prologue, nécessité de s'appuyer sur une construction rationnelle, mais aussi de rompre la linéarité du récit pour produire une attente, des effets de surprise, recherche de la vraisemblance dans les comportements et le propos des personnages. ${ }^{30}$

Nicht zuletzt ist es das folgende Zitat Quintilians, das Vida von der Rhetorik in die Poetik überträgt:

rectecque Cicero his ipsis ad Brutum verbis quadam in epistula scribit: „nam eloquentiam, quae admirationem non habet, nullam iudico." eandem Aristoteles quoque petendam maxime putat. ${ }^{31}$

Die admiratio spielt eine entscheidende Rolle, insofern als sie zum übergeordneten Ziel der Dichtung wird - erreicht durch den optimalen Einsatz der rhetorischen und stilistischen Mittel. ${ }^{32}$ Die Betonung der admiratio wird initiiert und begleitet vom feierlichen und bewundernden Ton von De arte poetica, den Leroux folgendermassen hervorhebt:

Le projet de Vida [...] est davantage une célébration de l'art qu'un exposé technique et systématique. ${ }^{33}$

\subsubsection{Die Initiation des Schülers}

De arte poetica dient der literarischen Erziehung von François de France, dem französischen Thronfolger, der 1527 neun Jahre alt war. ${ }^{34}$ Mit dem Lob und der stellenweisen Auslegung der virgilischen Texte versucht Vida, den Schüler für die Dichtung zu begeistern und ihn zur dichterischen Tätigkeit anzuregen.

30 PAPPE, Introduction, S. 11.

31 Inst. Orat., VIII, 3, 6: «So schreibt zurecht Cicero in einem Brief an Brutus die folgenden Worte:,Denn eine Beredsamkeit, die keine Bewunderung weckt, ist meines Erachtens gar keine.' Auch Aristoteles ist der Meinung, auf sie müsse es der Redner vor allem absehen. » Quintilian spielt auf Rhet., 1404b, an. Beide Stellen befinden sich in den jeweiligen Kapiteln zum Wortschmuck.

32 Was Schröder als « Ästhetisierung der Rhetorik» bezeichnet, ist somit nicht erst oder nicht nur ein Nebeneffekt der Auseinandersetzung mit der aristotelischen Poetik, sondern bereits bei Vida - und auch schon bei Poliziano, Pontano und Colonna - zu beobachten. Siehe SCH RÖDER, Logos und List, S. 42.

33 Leroux, Le genre de la Silve, S. 67.

34 Lecointe, Lidéal et la différence, S. 482. 
Vergils wunderbare Kunst («mira [...] arte», I, 167) ist so wirkungsstark, dass sie es schafft, Effekte des Staunens zu erzeugen:

Extulit os sacrum soboles certissima Phœbi

Virgilius, qui mox, veterum squalore, situque

Deterso, in melius mira omnia rettulit arte,

Vocem, animumque deo similis. date lilia plenis,

Pierides, calathis, tantoque assurgite alumno.

Unus hic ingenio præstanti, gentis Achivæ

Divinos vates longe superavit, et arte,

Aureus, immortale sonans. stupet ipsa, pavetque,

Quamvis ingentem miretur Græcia Homerum..$^{35}$ (I, Vv. 165-173)

Vergil wird als Nachkomme Apollons («Phoebi») bezeichnet: Die (zeitliche, kulturelle und sprachliche) Distanz zwischen den Griechen und den Römern wird aufgehoben, die Abstammung Vergils von den Göttern als gesichert dargestellt («soboles certissima»). Vergil verfügte über einen gottähnlichen Geist und eine ebensolche Stimme, weshalb es ihm nicht nur gelang, den Glanz der antiken Poeten fortzuschreiben, sondern er es dank seines Genies («ingenio ») und seiner Kunst (« arte») auch schaffte, die griechischen Dichter um ein Weites zu übertreffen («Divinos vates longe superavit») und damit die Griechen zu verblüffen («stupet ipsa [...] Græcia»). In dieser kurzen Passage sind bereits die beiden wichtigsten Bestandteile ausserordentlicher Dichtung genannt: die gottähnliche Persönlichkeit des Dichters auf der einen, der Effekt des Staunens bei den Lesern auf der anderen Seite.

Das Lob Vergils ist Ausgangspunkt eines metaphorischen Initiationsritus, der den Schüler in den Tempel der vates einführt und in der Bewunderung Vergils mündet:

Jamque igitur mea cura puer penetralia vatum Ingrediatur, et Aonia se proluat unda.

Jamque sacrum teneris vatem veneretur ab annis,

Ich zitiere aus : Marco Girolamo Vida, De arte poetica / L'art poétique, édition et traduction de Jean Pappe, Genève 2013. Die deutschen Übersetzungen aus De arte poetica stammen von der Autorin (A.E.). Sie sind angelehnt an die französischen Übersetzungen von Pappe: «Der eindeutigste Sprössling von Phoebus erhob seine heilige Stimme, / Vergil, der in kurzer Zeit den Schmutz und den Rost von den Alten / reinigte und mit dem Wunder seiner Kunst alles verbesserte, / seine Stimme und sein Geist sind den Göttern ähnlich. Füllt den Korb mit Lilien, / und erhebt euch, ihr Musen, vor dem grossen Schüler. / Er ist der Einzige, der mit seinem Genie und seiner Kunst / den göttlichen Poeten aus dem Geschlcht der Achäer vorsteht; / vor diesem göttlichen Wesen, seiner unsterblichen Stimme, staunen und beben selbst / die Griechen, auch wenn sie noch so sehr den grossen Homer bewundern. » 
Quem Musæ Minci herbosis aluere sub antris,

Atque olim similem poscat sibi numina versum,

Admirans artem. Admirans præclara reperta. ${ }^{36}$ (I, Vv. 109-114)

Die Dichtungslehren, die sich an den Initiationsritus anschliessen, bleiben in den Rahmen der Vergil-Verherrlichung und in den Gestus der admiratio eingebettet. ${ }^{37}$ Zudem müssen sie von der göttlichen Eingebung vollendet werden - ein Topos, den wir unter anderem auch bei Horaz ${ }^{38}$ vorfinden.

Et mea dicta parum prosint, ne desuper adsit

Auxilium, ac praesens favor omnipotentis olympi. ${ }^{39}$ (III, Vv. 531-532)

Die Inspiration ist dennoch in erster Linie durch den Menschen und nicht durch die Götter bestimmt, denn sie zeigt sich nur bei jenen Schülern, die sich von der wunderbaren Lieblichkeit der Dichtung gefangen nehmen lassen ( « sed mira operum dulcedine captus », I, V. 288). Zudem kann eine mangelnde Inspiration durch die (Re-)Lektüre der antiken Klassiker angeregt werden (II, V. 395). ${ }^{40}$

Am Ende des ersten Buches behandelt Vida den göttlichen Ursprung der Dichtung. Damit die Dichtung von den Göttern zu den Menschen gelangen konnte, bedurfte es einer List des Prometheus. Im Olymp hatte dieser die Musik der Sterne vernommen und war erstaunt über deren Klang («miratus sonitum », I, V. 522). Aus Mitleid mit dem primitiven und groben Geist der Menschen überkam ihn der Wunsch, den Menschen den Gesang der Musen gemeinsam mit dem Feuer zugänglich zu machen. Die Götter willigten ein, liessen Prometheus aber dennoch am kaukasischen Gipfel leiden - nicht aufgrund seines Geschenks an die Menschen, sondern seiner Kühnheit wegen. Die Menschen waren über Prometheus' Schicksal mit Schrecken erfüllt, sodass

$3^{6}$ Das ist nun folglich meine Bemühung für den Jungen, dass er in das Innere der Dichter / eindringt, und sich mit den aonischen Gewässern benetzt, / sodass er bereits im zarten Alter die göttlichen Dichter verehrt, / die die Musen in den grünen Grotten des Mincio ernährt hatten, / und er die Götter bittet, eines Tages selbst derartige Verse zu finden, / sodass seine Kunst und seine vortrefflichen Erfindungen bewundert und bestaunt würden.

37 Rhet., 1371a.

38 Horaz, Ars poetica. Die Dichtkunst, Lateinisch / Deutsch, herausgegeben und übersetzt von Eckhart Schäfer, Stuttgart 2008, Vv. 408-411.

39 Und meine Ratschläge wären wenig nützlich ohne Hilfe / von oben, ohne die offenkundige Gunst des allmächtigen Olymps.

40 Denizot, „Comme un souci“, S. 67. 
erst einige Zeit vergehen musste, bis sie es wagten, die Musen zu sich zu rufen (I, Vv. 516-532).

So blieb die Dichtung erst in den Händen der Götter, wo sie sich in Orakelsprüchen vollzog. Daher rühren die prophetische Wirkung der Dichtung sowie die Bezeichnung vates, die für den Propheten und den Dichter gleichermassen verwendet wird. Es war Zeus («pater divum », I, V. 534), der das erste Orakel gesungen hat; auf die griechischen folgten die hebräischen Propheten und dann die Sibyllen. Von den Propheten und Faunen gelangte der göttliche Gesang schliesslich zu den Menschen:

Nec mora, quæ primum Fauni, vatesque canebant,

Carmina mortales passim didicere per urbes,

Post epulas laudes heroum, et facta canentes. ${ }^{41}$ (I, Vv. 542-544)

Diese ersten Gesänge, nach Festmahlen gesungen, waren epische Gesänge: Loblieder auf die Helden. ${ }^{42}$ Die Vortrefflichkeit epischer Gesänge wird zu Beginn (I, Vv. 33-34) und am Ende (I, Vv. 543-544) des ersten Buches hervorgehoben und in dieser umrahmenden Wiederholung bekräftigt. Zudem soll «[d]ie mythische Erzählung [...] belegen, dass das Epos die älteste poetische Gattung sei, dass sich aus ihr sukzessive alle anderen Gedichtformen entwickelt hätten und dass epische Dichtung daher eine normative Geltung für andere Gattungen besitze ».

Die epischen Festgesänge sind ein Geschenk der Götter an die Menschen, um sie zu zivilisieren und ihren Geist zu erheben. Sie werden deshalb als das erstaunlichste Geschenk überhaupt beschrieben:

Quid mirandum homini cælo divinitus æque

Concessum? [... $]^{43}$ (I, Vv. 545-546)

Neben den Faunen und Propheten war es insbesondere Orpheus, der die Grossartigkeit und die ausserordentliche Wirkkraft der Dichtung zu überbringen vermochte. Die ganze Natur gehorchte seinem Göttergesang, der Schatten des Tartarus erbleichte und erstaunte («pallentes stupuere») gleichermassen vor ihm. Das Lob des Orpheus wird mit einem Opferritus

41 Ohne Rast, was zuerst von den Faunen und den Propheten gesungen wurde, / diese Gesänge lernten die Sterblichen überall in den Städten, / und nach den Mahlzeiten sangen sie von Ruhm und Taten der Helden.

42 Rolfes, Die lateinische Poetik, S. 111.

43 Was haben die Menschen durch göttliche Fügung vom Himmel erhalten, / das genauso erstaunlich war? 
bekräftigt, wobei der Erzähler sich als Dichter und Priester zu erkennen gibt, der in Begleitung seiner Schüler dem Orpheus heilige Geschenke überbringt.

Ipse tuæ egregios audax nunc laudis honores

Ingredior, vates idem, superumque sacerdos,

Sacraque dona fero teneris comitatus alumnis. ${ }^{44}\left(\mathrm{I}, \mathrm{Vv} .{ }_{561-563)}\right.$

Die Dichtergenealogie, die auf Orpheus zurückgeführt wird, haben wir bereits bei Poliziano angetroffen. Auch den Wagemut (audacia) als eine zentrale Eigenschaft des Dichters hat Poliziano in den Silvae genannt. ${ }^{45}$ Er wurde bereits von Quintilian betont und mit spezifischen, wirkungsstarken Mitteln in Verbindung gebracht:

praecipueque ex his oritur mira sublimitas, quae audaci et proxime periculum translatione tolluntur, cum rebus sensu carentibus actum quendam et animos damus $[\ldots]^{46}$

Illa adhuc audaciora et maiorum, ut Cicero existimat, laterum, fictiones personarum, quae $\pi p \circ \sigma \omega \pi \circ \pi$ olía dicuntur: mire namque cum variant orationem tum excitant. ${ }^{47}$

Im ersten Beispiel bezieht sich der Wagemut auf die Schaffung von Metaphern, die unbelebten Objekten lebendige Qualitäten zuschreiben. Im zweiten Zitat wird die Erfindung von Personen als ein wagemutiges Vorgehen ausgezeichnet, das auf erstaunliche Weise Abwechslung und Spannung schafft. Sowohl der metaphorischen Sprechweise wie auch der Fiktion werden wir in den folgenden Büchern von De arte poetica wieder begegnen.

\subsubsection{Inspiration, Invention und Komposition}

Zu Beginn des zweiten Buches bittet Vida die Musen darum, ihm neue Wege der Vermittlung von inventio und dispositio aufzuzeigen («novos ostendite

44 Ich bin so wagemutig - welch aussergewöhnliche Ehre! - und beginne / mit den Lobsprüchen auf dich, denn ich selbst bin ein Dichter, ein Priester der Götter, / und ich bringe heilige Gaben, begleitet von meinen jungen Schülern.

45 Vgl. Manto, Praefatio.

46 Inst. Orat., VIII, 6, 11: «Und manchmal aus solchen Metaphern, die in kühner und beinahe waghalsiger Übertragung gewonnen werden, entsteht wunderbare Erhabenheit, wenn wir gefühllosen Dingen ein Handeln und Leben verleihen [...]».

47 Inst. Orat., IX, 2, 29: "Noch mehr Kühnheit und - mit Ciceros Worten - stärkere Lungenkraft verlangt die Erfindung von Personen, die sogenannte Prosopopoiie; denn aufs wunderbarste verleiht sie der Rede nicht nur Abwechslung, sondern zumal auch erregende Spannung. » 
calles», II, Vv. 7, 11-16). Die Bitte um «novos [...] calles» verdeutlicht, dass Vida die Prinzipien, die er seinen Schülern lehrt - an dieser Stelle die Neuheit des dichterisch Dargestellten -, auch im didaktisch angelegten Lehrgedicht unmittelbar umzusetzen versucht.

Während die inventio durch göttliche Eingebung erfolgt und der Geduld aufseiten des Dichters bedarf (II, Vv. 13-14), können dispositio und elocutio als Kunstfertigkeit erlernt werden (II, Vv. 15-16). Die inventio scheint in wenigen Zeilen abgehandelt:Wem (ein) Gott wohlgesinnt ist, dem wird der gewünschte Stoff unerwartet einfallen (II, Vv. 13-14). Ist der Stoff erst einmal gefunden, stellt sich die Frage der adäquaten Darstellung. Erst gegen Ende des zweiten Buches kommt Vida noch einmal auf die Auswahl des Stoffes zu sprechen und präzisiert folgendermassen: Da die Leser bei Wiederholungen zur Ermüdung neigen, empfiehlt Vida die Bearbeitung eines wenig bekannten Inhalts, der zudem in neuer Gestalt erscheinen soll (II, Vv. 229-341). Der Stoff soll nicht frei erfunden sein, sondern aus dem Griechischen in die lateinische Sprache überführt werden (II, Vv. 546-548).48 Dieses Vorgehen wird mit einer heroischen Metapher veranschaulicht: Der zukünftige Poet wird aufgefordert, die Reiche der Griechen mit seinen Augen auszukundschaften («[e]xplorare oculis »).

Inventa ex aliis disce: et te plurima Achivos

Consulere hortamur veteres, Argivaque regna

Explorare oculis, $[\ldots]^{49}$ (II, Vv. 542-544)

Diese Metapher wird weitergeführt, wenn der Leser aufgefordert wird, den Glanz von Vergils Erscheinung zu vergegenwärtigen - von Vergil, der seinerseits die Rüstung Homers „erobert“ hat.

Aspice ut insignis peregrino incedat in auro

Fatidicæ Mantus, et Minci Filius amnis,

Fulgeat et magni exuvias indutus Homeri,

Nec pudet. [... $]^{50}$ (II, Vv. 549-552)

48 Vida sieht die antiken Griechen als Wegbereiter der grossartigen Literatur. Die lateinischen Dichter ihrerseits hätten dieses Erbe überhöht und noch glorioser gemacht - das antike Rom wurde zur bedeutendsten aller Städte, und das nicht nur der Literatur, sondern auch der Kriegskünste. Vida bittet Apollon darum, diese Glorie weiterhin zu erhalten, auch wenn die Kriegskünste den „Römern“ nicht mehr gutgesinnt seien und fremde Mächte Italien einzunehmen drohen. Siehe II, Vv. 542-571.

49 Lerne die Erfindungen anderer kennen: Ich ermutige dich vor allem, / die alten Griechen zu konsultieren, erkunde die Reiche der Argiver / mit deinen Augen, [...]

5o Schau mit welcher Zierde er einherschreitet, eingehüllt in fremdländisches Gold, / Sprössling der schicksalsverkündenden Manto und des Flusses Mincio, / und wie er glänzt, eingekleidet in die Rüstung des grossen Homer, / für die er sich nicht schämt. 
Die Übersetzung und Nachahmung griechischer Texte sowie die Anreicherung des kulturellen Erbes Latiums werden zur Heldentat erklärt, der (angehende) Dichter mit dem Helden gleichgesetzt. Mit dieser Metapher wird erneut Vidas Vorliebe für epische Stoffe ${ }^{51}$ kundgetan. Vida legt dem Schüler zwar nahe, die Wahl von Inhalt und Genre nach seinen persönlichen Fähigkeiten auszurichten (I, V. 40), preist aber zugleich den Hexameter sowie die Götter- und Heldengesänge als Vorbilder aller Dichtung. Der Hexameter sei das ursprüngliche Metrum gewesen, das Apollon seiner Tochter Phemonoé zur Verwendung in den Orakeln geschenkt habe. Analog dazu "schenkt" auch Vida seinem Schüler das epische Metrum - denn vom epischen Stil lassen sich alle weiteren Stile ableiten (I, Vv. 33-43).

Ist der Stoff erst einmal klar umrissen und das Genre bestimmt, ist es die zentrale Aufgabe des Dichters, die Aufmerksamkeit der Leser zu erregen und aufrechtzuerhalten.

Protinus illectas succende cupidine mentes,

Et studium lectorum animis innecte legendi. ${ }^{52}$ (II, Vv. $38-39$ )

Laut Vida soll das ganze Werk als spannende Zeichenfährte zu einem vollständigen und kohärenten Schlussbild konzipiert sein, was mit folgendem Bild verdeutlicht wird: Gleichsam als würde der wolkenverhangene Himmel sich nach und nach lichten, wird am Ende des Werkes ein klares Bild sichtbar (II, Vv. 4O-45).53

Teil des Fährtenspiels sind die folgenden Mittel, die besonders effektiv zur Schaffung von Aufmerksamkeit beitragen: Spannung, Überraschung, Fiktion und innovatio (II, Vv. 56-57, 98-100, 339-341). Zu Beginn sollen in einem Aperçu die zentralen Inhalte angedeutet werden. Der Text soll an dieser Stelle weder schwülstig sein noch der Inhalt zu gewaltig dargestellt werden, um das Grossartige nicht bereits zu Beginn zu verspielen, sondern für spätere Szenen aufzubewahren. Begonnen wird in medias res, und zwar bereits in der Nähe des Endes, sodass der Leser voller Spannung die Auflösung erwartet, sich dem Erzähler aber gleichzeitig Möglichkeiten bieten, die Geschichte retrospektiv aufzufalten.

$5^{1} \quad$ Unzählige Stellen untermauern diesen Vorzug: II, Vv. 283-289; III, Vv. 177-184, 367-369, 411-414, 440-442.

52 Beginne unverzüglich, den Leser zu verführen und das Verlangen seines Geistes zu entfachen, / umschlinge seine Seele mit der Lust des Lesens.

53 Vgl. dazu Inst. Orat., VIII, 3, 63: «Eine Art besteht also darin, gewissermassen in Worten ein Gesamtbild der Dinge abzuzeichnen [...]». 
Primus at ille labor versu tenuisse legentem

Suspensum, incertumque diu, qui denique rerum

Eventus maneat, $[\ldots]^{54}$ (II, Vv. 98-100)

Es ist die Aufgabe des Dichters, auf die Konstruktion seines Werkes besonderes Augenmerk zu richten: Nichts soll willkürlich, alles soll den Regeln der Vernunft entsprechend angeordnet sein (II, Vv. 156-159). Dabei soll der Leser die Konstruiertheit des Textes nicht bemerken; dieser soll natürlich gefügt erscheinen oder durch bewusste Ausschweifungen die strikte Konstruktionslinie verbergen (II, Vv. 213-214, 226-227). Ex negativo werden in Bezug auf die stringente Konstruktion das Lob und die Bewunderung eingebracht:

\section{[...] tecumque premendo}

Totum opus ædifices, iterumque, iterumque retractes

Laudatum alterius frustra mirabere carmen.

Nec te fors inopina regat, casusque labantem.

Omnia consilis provisa, animoque volenti

Certus age, ac semper nutu rationis eant res. ${ }^{55}$ (II, Vv. 157-162)

Schafft der Dichter es nämlich nicht, seine Konstruktion vollständig nach den Regeln der Vernunft zu gestalten, werden Lob und Bewunderung einem anderen zuteil (« [l] audatum alterius frustra mirabere carmen»).

Wiederholt wird das Empfinden des Lesers zur Orientierung ins Feld geführt: Was erzählt wird, muss dem Erzählten und seiner Dynamik angemessen sein. Inmitten einer rasanten Kampfszene interessiert sich der Leser nicht für eine ausführliche Ekphrasis oder unglaubwürdig lange Dialoge (II, Vv. 179-185, 307310). Ebenso muss der Autor stets auf die Reaktion bedacht sein und an jenen Stellen, an denen der Leser erschöpft sein könnte, einen lieblichen Gesang einfügen (II, V. 241) oder das Thema und die Perspektive variieren (variatio, II, Vv. 220-225). Für das Vergnügen des Lesers dürfen prägnante sententias, die das angenehme Leben der Menschen betreffen (II, Vv. 278-279), nicht fehlen diese bleiben in Erinnerung und werden weitergegeben (II, V. 281).

Fiktive Einschübe dienen ebenfalls dazu, die Aufmerksamkeit der Leser aufrechtzuerhalten («dulcia [...] teneant mendacia mentes», II, V. 316).

54 Die wichtigste Aufgabe ist es, den Vers so zu gestalten, dass er den Leser / fesselt, er lange unsicher bleibt / über den Ausgang der Handlung.

55 Wenn du dich nicht konzentrierst / auf die Konstruktion des gesamten Werkes, du es nicht wieder und wieder überarbeitest, / wird der Gesang eines anderen das Lob und dein vergebliches Staunen ernten. / Lasse dich nicht wankend von einem plötzlichen Zufall leiten. / Bemühe dich, alles vorherzusehen, bewege sicher / den geneigten Geist, sodass die Dinge immer der Vernunft folgen. 
Wenngleich die Dichtung der Wahrheit und der Wirklichkeit grundsätzlich ähnlich sein soll («saltem sint simillima veris », II, V. 306), stellen Fiktionen Momente dichterischer Freiheit dar, die ausserhalb der Kategorien des Wahren und Wahrscheinlichen wirken - so ist jedem Leser stets bewusst, dass es an bestimmten Stellen nicht um wörtliche Glaubwürdigkeit, sondern um spezifisch literarische Effekte geht (II, Vv. 315-319).

Fiktionen sind unterschiedlich ausgerichtet, je nachdem, wie neu ihr Inhalt ist. Bekannte Bilder und Erzählungen verweisen oft auf antike Mythen und stellen diese in einen neuen Kontext. Neu erfundene, fiktive Einschübe erregen Aufmerksamkeit und Staunen (II, Vv. 320-324), insbesondere weil sie die Anschaulichkeit des Erzählten verstärken. ${ }^{56}$ Die Kraft der énargeia ${ }^{57}$ kann sich entfalten, wenn Worte und Inhalt sich übereinanderlegen (II, Vv. 367-368) und das Erzählte nicht als Gesagtes erscheint, sondern unmittelbar - für die Ohren und Augen des Lesers - wahrnehmbar wird (II, Vv. 382-394). Vida verweist implizit auf die énargeia, indem er eine Stelle der Institutiones Oratoriae (VIII, 3, 67-69) in seine Poetik integriert (II, Vv. 377-392). Es handelt sich um die Schilderung einer kriegerischen Einnahme einer Stadt, angelehnt an das zweite Buch der Aeneis und die kriegerische Eroberung Trojas. Die Stelle zeigt auf eindrückliche Art und Weise, wie Vida den literarischen Text Vergils und Quintilians Rhetoriklehre übereinanderlegt, um seinem Schüler sowohl die Lehre als auch die literarische Umsetzung der evidentia und deren Wirkung zu „veranschaulichen“. Dargestellt werden eine angegriffene Stadt, in der die Schläge und Schüsse der Waffen genauso wahrnehmbar werden wie die Flammen, die sich von Gipfel zu Gipfel ausbreiten, und die Menschen, die verzweifelt durch die Gassen rennen. Erzählt wird in einer schnellen StakkatoSprache, wobei unter anderem durch die häufige Verwendung des Suffixes «-que» die regelmässig ertönenden Schüsse angedeutet werden und durch die vielen S-Laute das Zischen der Flammen dargestellt wird. Die Onomatopoesie ergänzt das wirkungsstarke Mittel der énargeia, sodass ein lebendiger Gesamteindruck entsteht:

56 Vgl. dazu Inst. Orat., VIII, 3, 70.

57 Die énargeia ist neben der aristotelischen enérgeia ein Teil der evidentia. Während die enérgeia die sprachliche Fähigkeit meint, Dinge lebendig erscheinen zu lassen, geht die énargeia zum einen auf die Idee einer detailliert-bildlichen Beschreibung, zum anderen auf die Vorstellung absoluter, mental-bildlicher Evidenz zurück. Die Stoiker haben die énargeia als Ursprung der Emotionen betrachtet - von daher rührt die Zugehörigkeit der evidentia zur Rhetorik der Affekte. Auch für Quintilian - eine der wichtigsten Quellen Vidas - existiert eine Korrelation zwischen den Bildern, die der Redner kreiert, und den Emotionen, die daraus bei den Zuhörern entstehen (Inst. Orat., VI, 2, 29-30). Siehe dazu ebenfalls das Lemma «Evidentia, Evidenz» im Historischen Wörterbuch der Rhetorik; zudem Galand-Hallyn, Les yeux de l'éloquence, S. 99, 136, 148. 
Pour Vida, l'enargeia est fondamentale; sans la nommer, il la rendit particulièrement prégnante aux yeux de ses contemporains par des exemples et des illustrations particulièrement virtuoses. Pour Vida, le rôle des poètes héroïques est de donner à voir une image forte, qui mobilise tous les sens dans une tension visionnaire. ${ }^{58}$

Die veranschaulichende und verlebendigende Kraft der Sprache löst die Vorrangstellung der Allegorie ab. Der Bildcharakter gewinnt einen ästhetischen Wert, während der moralische Gehalt in den Hintergrund rückt oder gar verschwindet.

[...] puisque c'est désormais la vive représentation qui fait connaître les choses, plus que la fable. [...] Ainsi le pouvoir de la poésie sur les esprits est avant tout esthétique et non pas moral. ${ }^{59}$

Am Ende des zweiten Buches kommt der Text auf die inspiratio zu sprechen. Diese beginnt mit dem „heiligen Furor“ (« sacer [...] furor », II, V. 395), den die Götter in die Seelen der Dichter einflössen (II, V. 404).

[...] Unde hæc tam clara repente

Tempestas? Deus ecce deus jam corda fatigat,

Altius insinuat venis, penitusque per artus

Diditur, atque faces sævas sub pectore versat.

Nec se jam capit acer agens calor, igneaque intus

Vis sævit, totoque agitat se corpore numen.

Ille autem exsultans jactat jam non sua verba,

Oblitusque hominem, mirum sonat. Haud potis ignem

Excutere. Invitum miratur se ire, rapique

Præcipitem te, Phœbe, vocans te, Phœbe [... $]^{60}$ (II, Vv. 428-437)

58 Chevrolet, L'idée de la fable, S. 533.

59 Denizot, „Comme un souci“, S. 70.

6o Woher kommt plötzlich dieser leuchtende / Sturm? Es ist ein Gott, ja ein Gott, der die Herzen heimsucht, / von hoch oben erfüllt er die Venen, verteilt sich ins Innerste der / Glieder und quält die Brust mit heftigen Flammen. / Ein heftiges und lebhaftes Fieber erfasst ihn, eine feurige Kraft tobt / im Innern, im ganzen Körper bewegt sich die Gottheit. / Und er, in Ekstase, ruft Worte aus, die nicht die seinen sind, / vergessen das Menschsein, erklingt Wundersames. Du kannst die Flammen nicht / abschütteln. Widerwillig geht er, staunend und ergriffen, / jäh ruft er dich an, Phöbe, Phöbe [...] // RolfEs, Die lateinische Poetik, S. 211-212: « Vom platonischen Enthusiasmos [...] sind für Vidas ,furorLehre drei Aspekte relevant: Erstens ist dieser göttliche Wahn für den dichterischen Erfolg obligatorisch. Zweitens schließt die Begeisterung jede rationale Kontrolle aus. Und drittens sprechen Dichter im Enthusiasmos nicht durch eigene Kraft, sondern als Begeisterte bzw. Besessene. » 
Der göttliche Furor dringt in den Körper des Dichters ein und erfüllt selbst dessen innerste Glieder. Fieber («acer [...] calor») - eine feurige Gewalt («igneaque [...] vis ») - steigt in ihm auf. In diesem körperlichen und geistigen Extremzustand spricht er Worte aus, die nicht die seinen und nicht mehr menschlich sind: Sie klingen seltsam («mirum sonat»). Der Ergriffene ist über sich selbst erstaunt («miratur se ») und kann gar nicht anders, als sich fortreissen zu lassen und Phoebus um Hilfe anzurufen.

Das Staunen in Bezug auf die während des Furors ausgesprochenen Verse ist leicht negativ konnotiert, ähnlich dem Staunen des Dichters über seine Verse, bevor er nach einer Ruhephase beginnt, diese ausführlich zu revidieren.

Miratur tacitus, nec se cognoscit in illis

Immemor, atque operum piget, ac se se increpat ultro.

Tum retractat opus, commissa piacula doctæ

Palladis arte luens. Nunc hæc, nunc rejicit illa,

Omnia tuta timens, melioraque sufficit illis,

$[\ldots]^{61}$ (III, Vv. 478-482)

Gestaunt werden kann also nicht nur über herausragende dichterische Verse, sondern auch über die eigenen Verse, die noch nicht dem finalen Zustand entsprechen. ${ }^{62}$ Dieses Staunen ist notwendig, um die intensive und Geduld einfordernde Überarbeitung zu initiieren, sodass am Schluss das negative in ein positives Staunen umschlägt und der Ruhm des Dichters bis in himmlische Höhen steigt (III, Vv. 516-524).

Der göttliche Ursprung der Dichtung markiert nur den Beginn des poetischen Schaffens. Es wird eine klare Trennung zwischen irrationaler und rationaler Phase - wenn auch in einer gegenseitigen Abhängigkeit der beiden Phasen voneinander - postuliert. Die rationale Arbeit am Text ist nicht nur wichtig, um dem Furor die Zügel (II, V. 450) anzulegen, sondern auch, um die Effekte auf die Leser genau zu steuern.

61 Er verstummt erstaunt, erkennt sich nicht wieder in seinen Versen, / ist ohne Erinnerung; verdrossen über sein Werk schilt er sich selber. / Dann nimmt er sein Werk wieder auf und sühnt sich mit der Kunst / der gelehrten Pallas. Er verwirft diesen und jenen Vers, / verdächtigt auch alle scheinbar fehlerfreien Stellen und wählt bessere aus, / [...]

62 Verursacht wird dieser Zustand zwischen Erstaunen und Scham insbesondere durch die zu grosse und uneinheitliche Vielfalt - deshalb die Aufforderung, die üppige «silva » (III, Vv. 483-485) zu stutzen und alle Verse, die nicht zur Verbesserung des Textes beitragen, zu entfernen. Diese Äusserung ist sicherlich angelehnt an Quintilians Kritik an der Silva, die seiner Meinung nach ein zu schnell und euphorisch hingeschriebenes sowie unstrukturiertes Genre darstellt, das erst noch der Überarbeitung bedarf. Vgl. Inst. Orat., $\mathrm{X}, 3,17$. 
Discitur hinc etenim sensus, mentesque legentum

Flectere diversosque animis motus dare, ut illis

Imperet arte potens dictu mirabile vates.

Nam semper, seu læta canat, seu tristia mœrens,

Affectas implet tacita dulcedine mentes. ${ }^{63}$ (II, Vv. 510-514)

Durch den gezielten Einsatz rhetorischer Mittel erzielt der Dichter Effekte wie Wut, Mitleid, Schmerz, Scham, Liebe, Begehren (II, Vv. 515-532) und löst zugleich auf einer metapoetischen Ebene Staunen über sein Können aus.

Obwohl im zweiten Buch die spezifischen rhetorischen Mittel der dispositio abgehandelt werden, bleibt das Staunen eingebettet in den Rahmen, der dem Schüler die Begeisterung für die antiken Dichter zu vermitteln sucht. Entsprechend trägt die Strukturierung des dichterischen Werkes auf einer übergeordneten Ebene zur admiratio bei.

\subsubsection{Die sprachliche Ausgestaltung des Textes}

Im dritten Buch erläutert Vida jene Beschaffenheit der Ausdrücke (III, V. 1), die aufgrund ihrer Vielfalt die Grundlage des Lesevergnügens darstellen. Die Ohren und das Herz sollen dabei gleichermassen angesprochen werden:

Nunc hanc, nunc aliam ingredere, et mutare memento, jamque hos, jamque alios haud segnis sumere vultus. Nempe inde illectas aures immensa voluptas Detinet, et dulci pertentat pectora motu. ${ }^{64}$ (III, Vv. 35-38)

Die Vielfalt der Sprache ist angelehnt an die immense Vielfalt der Natur (III, Vv. 39-43), wobei Vida wie Poliziano und Pontano nicht nach einer realistischen Nachahmung der Natur, sondern nach der Mimesis ihrer Vielfalt sucht. Das Einzigartige der Dichtung ist es nämlich, dass diese vielfältigen Objekte nicht mit existierenden Worten («verbis [...] veris») dargestellt - die „reellen“ Vokabeln werden zurückgelassen («relictis») -, sondern neue Vokabeln zu ihrer Darstellung herbeigeholt werden («accersant simulata », III, Vv. 44-45). Diese neuen Bezeichnungen kleiden die dargestellten Objekte in ungewohnte

63 Von hier lernt er die Sinne und den Geist der Leser zu berühren, / ihre Seelen in verschiedene Richtungen zu bewegen, sodass er / mit seiner Kunst - erstaunlich zu sagen als mächtiger Dichter über sie herrscht. / Denn immer, ob er Fröhliches besingt oder ein Unglück betrauert, / schafft er Emotionen und erfüllt die Gemüter mit einer geheimnisvollen Lieblichkeit.

64 Beginne einmal mit dieser, einmal mit jener Figur und denk daran, abzuwechseln, / wende einmal diesen, einmal jenen Ausdruck an. / Denn daher kommt das unendliche Vergnügen, das unsere Ohren verführt, / es hält sie fest, und durchdringt unsere Herzen mit einer lieblichen Empfindung. 
Gewänder, sodass diese über ihre neue Erscheinung erstaunt und erfreut sind und nicht mehr zu ihren alten Bezeichnungen zurückwollen. Diese Metapher setzt den Auftakt zu Vidas Reflexion über die Metapher ${ }^{65}$ - wie bereits mehrfach gesehen, setzt Vida unmittelbar um, was er zu vermitteln sucht.

[...] sæpe externi mirentur amictus

Unde illi, lætæque aliena luce fruantur,

Mutatoque habitu; nec jam sua nomina mallent?66 (III, Vv. 48-50)

Usque adeo passim sua res insignia lætæ

Permutantque, juvantque vicissim, et mutua se se

Altera in alterius transformat protinus ora.

Tum specie capti gaudent spectare legentes. ${ }^{67}$ (III, Vv. $58-61$ )

Die Freude der Dinge über ihre sprachliche Vielgestaltigkeit und Verwandlung überträgt sich auf den Leser, wenn dieser die illusorische, sich wandelnde Sprachoberfläche bestaunt («spectat»). Dieses Phänomen wird anhand eines weiteren Bildes veranschaulicht:

Nam diversa simul datur e re cernere eadem

Multarum simulacra animo subeuntia rerum.

Ceu com forte olim placidi liquidissima ponti

Aequora vicina spectat de rupe viator,

Tantum illi subjecta oculis est mobilis unda:

Ille tamen silvas, interque virentia prata

Inspiciens miratur, aquæ quæ purior humor

Cuncta refert, captosque eludit imagine visus. ${ }^{68}$ (III, Vv. 62-69)

65 PAppe, Commentaire, S. 177, Fn. 133. Pappe verweist an dieser Stelle auf auch Inst. Orat., VIII, 6. Vida thematisiert in der Folge auch die Metonymie (III, Vv. 123-125), die contradictio (III, Vv. 136-138) und den Vergleich (III, Vv. 163-169). Im Gegensatz zur Metapher wird das Staunen in Bezug auf diese rhetorischen Mittel nicht erwähnt.

66 Diese Dinge, die fremden Gewänder bestaunend, fragten sich oft, / woher sie kämen, und erfreuten sich fröhlich am ungewohnten Glanz / und am veränderten Aussehen; nicht einmal ihrem ursprünglichen Namen waren sie mehr gewogen.

67 In einem fort wechseln die Dinge heiter ihre / Vorzeichen, sie erfreuen uns der Reihe nach und verwandeln sich / gegenseitig, das eine in das Antlitz des anderen. / Von diesem Anblick gefesselt erfreuen sich die Leser am Zuschauen.

68 Denn ein und dieselbe Sache gibt uns gleichzeitig verschiedene Dinge zu erkennen. / Das sind die vielfältigen Bilder, die in den Geist eindringen. / Gleich wie ein Reisender, wenn er von einem nahen Felsen / die klare Oberfläche des ruhigen Meeres betrachtet, / so befindet sich vor seinen Augen nur eine sich bewegende Welle: / Dennoch kann er darin staunend die Wälder, umgeben / von grünen Wiesen, betrachten. Denn im Wasser, ganz rein, / spiegelt sich alles, der Blick ist gefesselt und getäuscht von einem Bild. 
Für den Leser verhält es sich wie für den Reisenden, der von einem Felsen aus auf das ruhende und glatte Meer blickt und dort im Lichtspiel illusorische, vielgestaltige Spiegelungsreflexe erblickt. ${ }^{69}$ Er betrachtet die literarischen Bilder mit Staunen («[i]nspiciens miratur ») - wohlwissend, dass es sich um poetische, nicht um reelle Bilder handelt. ${ }^{70}$

Die literarische Metapher ist Ausdruck des kreativen und visuellen Charakters der Dichtung. Sie zeichnet sich insbesondere dadurch aus, dass sie ungewohnte Verbindungen herstellt und neue Bilder schafft. Als solche unterscheidet sie sich von der Metapher, wie sie beispielsweise von den Rednern oder gar von den Bauern geschaffen und angewandt wird. Der Redner benutzt Metaphern zur Visualisierung und zur Überzeugung des Richters, der Bauer bedient sich Ausdrücken wie "durstige Wiesen“ oder "lachende Felder" (II, Vv. 84-95), weil ihm keine passenden Worte zur Verfügung stehen. Wie schon Pontano entbindet auch Vida den Dichter von jeglicher Zweckgebundenheit und spricht ihm, im Gegensatz zum Redner und zum Bauern, Ausdrucksfreiheit zu. Diese Freiheit steht ihm bei der Bildung von Sprachbildern genauso zu wie in der Gestaltung des Versmasses. Als Vorbilder der kreativen Ausdrucksweise dienen die « vates » - die Dichterpropheten -, denn die raffinierte Ausschmückung («cultus magis») zählt genauso zu ihrem sprachlichen Inventar wie die ungewohnten rhetorischen Figuren («colores / Insoliti», III, Vv. 114115). Resultat der aussergewöhnlichen Ausdruckskraft sind die «miris [...] dictis », die erstaunlichen Äusserungen:

Crebrius hi fando gaudent super æthera miris Tollere res (nec sit fas tantum credere) dictis. ${ }^{71}$ (III, Vv. 116-117)

69 Das Moment des Lichts ist zentral in Vidas Lehre der elocutio: Der Dichter hat die Fähigkeit, mit seinem Sprachspiel die Dinge zu erleuchten und zum Glänzen zu bringen (III, Vv. 20-21, 73-74). Gleichzeitig ist er dazu aufgerufen, nur jene Worte auszuwählen, die Licht, Glanz und Ausstrahlung bringen (III, Vv. 179-184). Während also für die inspiratio das Feuer eine zentrale Rolle spielt, ist es in Bezug auf die elocutio das Licht, das im Vordergrund steht. Im Gegensatz zum Feuer hat das Licht keine zerstörerische, sondern eine strahlende Wirkung.

70 Der ausgedehnte Diskurs über die Metapher (III, Vv. 39-97) steht in Zusammenhang mit der énargeia, die bereits im zweiten Buch ausführlich behandelt wurde. Schon Quintilian hatte diesen Zusammenhang hergestellt, siehe Inst. Orat., VIII, 6, 19; ebenso VI, 2, 32: «Denn die Metapher ist größtenteils dazu erfunden, auf das Gefühl zu wirken und die Dinge deutlich zu bezeichnen und vor Augen zu stellen [...] »

71 Häufig gefällt es ihnen, die Dinge mit erstaunlichen Worten in die höchsten Sphären / zu heben (ohne dass man diese glauben müsste). 
« $[\mathrm{M}]$ iris $[. .$.$] dictis » umschliesst die beiden Zeilen als Endreim: In der ersten$ Zeile wird der Effekt der Erhebung über den Äther hinaus beschrieben, in der zweiten Zeile werden Inhalt und Ausdruck zusammengebracht. Die miris dictis sind das Wesentliche der Dichtung, während ihre Glaubwürdigkeit von geringer Relevanz ist («nec sit fas tantum credere », vgl. ebenso III, V. 112).

Wie aber gelangt nun der junge Dichter zu solchen Ausdrücken? Indem er aus dem Wald der Worte (III, V. 180) jene auswählt, die in ihrer Schönheit und ihrem Glanz herausragen (III, V. 181). Zu ihnen findet der Schüler in erster Linie über die Lektüre der antiken Meister (III, Vv. 185-192). Diese Meister dürfen und sollen nachgeahmt werden, allerdings immer in eigenständiger und neuartiger Art und Weise: « Nova sit facies, nova prorsus imago. »72 (III, V. 220) Eine gelungene und überraschende Wortwahl gilt als « erstaunliche Kunst» («mira arte », III, V. 226), ${ }^{73}$ wobei auch hier die Maxime der optimalen Balance - in diesem Falle zwischen Nachahmung und Eigenständigkeit - bemüht wird (III, Vv. 264-265).

Weitere Teile dieser Balance sind die Angemessenheit von Klang und Rhythmus an den dargestellten Inhalt sowie die Verbindung von Leichtem und Schwerem (III, Vv. 373-376), Schönem und Hässlichem (III, Vv. 377-381), Stürmischem und Ruhigem (III, Vv. 385-396) - diese Ausgewogenheit bildet die klassische Grundlage, für die Vida von Boileau und Pope zitiert und verehrt wurde, und sie löst im Leser Staunen aus («mirabere legendo », III, V. 397): $7^{74}$

Omnia sed numeris vocum concordibus aptant,

Atque sono quæcumque canunt imitantur, et apta

Verborum facie, et quæsito carminis ore. ${ }^{75}$ (III, Vv. $367-369$ )

Das dritte Buch endet, wie das erste Buch begonnen hat: mit einer Lobrede auf Vergil. Die Bewunderung des grossen lateinischen Dichters und seines Werkes umrahmen damit die drei Bücher von De arte poetica und schliessen ihre Inhalte in diesen Rahmen ein.

Omnis in Elysiis unum te Græcia campis

Miraturque, auditque ultro, assurgitque canenti.

Te sine nil nobis pulchrum. Omnes ora Latini

72 Neu sei das Antlitz, völlig neu das Bild.

73 Vgl. I, V. 167 und die dortige Bezeichnung von Vergils Kunst als «mira [...] arte».

74 PAppe, Commentaire, S. 211, Fn. 165.

75 Sie passen die Äusserungen immerzu dem entsprechenden Rhythmus an, / und sie ahmen, wenn sie singen, auch den Klang nach und geben / den Worten die richtige Gestalt und dem Gesang das passende Antlitz. 
In te, oculosque ferunt versi. Tua maxima virtus

Omnibus auxilio est. [... $]^{76}$ (III, Vv. 568-572)

Vergil hat es nicht nur ins Elysium geschafft, sondern er ist dort auch der einzige (lateinische) Dichter, der von den Griechen bestaunt und bewundert wird. Als Dichtervater wird er in den letzten Zeilen als Inspirationsquelle angerufen:

[...] Salve, sanctissime vates.

$[\ldots]$

Advenies, pater, atque animis te te infere nostris. ${ }^{77}$ (III, Vv. 588-592)

\subsection{Exkurs: Prometheus und die Zivilisierung des Menschen durch das Staunen}

Poliziano wie auch Vida beschreiben die mythologische Erhebung der conditio humana aus einem primitiven in einen kultivierten Zustand. Beide thematisieren, dass das Feuer des Prometheus allein nicht ausreichte, um die Menschen zu zivilisieren: Erst die Dichtung schaffte es, den geistigen Zustand der Menschen zu erhöhen und so einen Zugang zu gesellschaftlichen Regeln, Wissen und dem Göttlichen zu schaffen.

Bei Poliziano: Gott war müde vom geistigen und emotionalen Stumpfsinn der Menschen, woraufhin er beschloss, ihnen die « divina Poesia » als Führerin der menschlichen Seelen zu schicken und damit ihre Begierden zu zügeln, die Faulen anzutreiben und die Ungehobelten zu erziehen (Nutricia, Vv. 67-74).

Da Dichtung die Gesellschaft an sich erst begründet, ist es nicht mehr nötig, ihr einen Stellenwert innerhalb der Gesellschaft zu erkämpfen, wie es noch in der frühen Renaissance versucht wurde. ${ }^{78}$

Die Poesia erhält die Aufgabe, den fast verglühten prometheischen Funken in den Herzen der Menschen zu nähren und das göttliche Feuer in ihnen (wieder) zu entfachen. Damit wird das prometheische Feuer als innerliches

$7_{6}$ In den elysischen Gefilden bestaunt dich ganz Griechenland / als einzigen, sie hören $\mathrm{zu}$ und erheben sich bei deinem Gesang. / Ohne dich ist unsere Schönheit nichtig. Alle Lateiner haben ihr Gesicht / dir zugewandt, auf dich richten sie ihre Augen. Deine unbeschreibliche Kraft / kommt allen zu Hilfe. [...]

77 Wir grüssen dich, heiligster aller Poeten. / [... / Komm, du unser Vater, und dringe in unsere Seelen ein.

78 Rolfes, Die lateinische Poetik, S. 132. 
Feuer interpretiert - das ohne die Poesia verkümmert wäre. ${ }^{79}$ Prometheus selbst erscheint als einer der ersten vates (Nutricia, V. 202), der Orakel verkündet (V. 200). Zudem tritt er als Figur auf, die die Begierden der Menschen ausgleicht. So rettet er einen Satyr vor dem Feuer, das dieser zu sehr begehrt hat.

Der Mythos, wie Vida ihn erzählt, fokussiert auf einen anderen Aspekt: Prometheus bringt den Menschen nicht nur das Feuer, sondern auch die Sterne - eine Metapher für die Musen (I, Vv. 516-518). Die Musik der Sterne, die von den Musen geleitet wird und Prometheus in Erstaunen versetzt, scheint Prometheus neben dem Feuer das nützlichste Geschenk an die Menschen zu sein. Das Staunen ist damit wesentliche Ursache für die Entscheidung des Prometheus, den Menschen die himmlischen Klänge und die Musen weiterzugeben. Eine Analogie könnte man zur Aufforderung Vidas an seine Schüler ziehen, die „Reiche“ der antiken Griechen und Römer auszukundschaften und deren „Schätze“ in die zeitgenössische Dichtung zu überführen. Der „Diebstahl" wird den Schülern in Anlehnung an Prometheus gar ans Herz gelegt (III, Vv. 223-227). In Bezug auf das "Diebesgut" gilt - wiederum in Analogie zu Prometheus - das Staunen als Ursache der Überführung in die neue Welt.

Wie der Prometheus-Mythos zeigt, bedeutet „Diebstahl“, etwas aus Bewunderung und Wertschätzung aus einem fremden in den eigenen Bereich zu übertragen, um es dort nutzbringend einzusetzen. ${ }^{80}$

Die Götter genehmigen dieses göttliche Geschenk (I, V. 527) zwar, züchtigen Prometheus aber gleichzeitig für seinen übermässigen Wagemut. Das Titanische und Heldenhafte ist eine Charakteristik sowohl des Prometheus als auch des Dichters. Denn auch im Falle Vergils fühlen sich die Götter aufgrund dessen dichterischer Kühnheiten vor den Kopf gestossen und verblüfft.

Avec Vida, Prométhée devient donc le prototype du Poète. L'assimilation du Titan à l'artiste créateur s'était déjà trouvée chez Filippo Villani [...] en dehors de Villani, de Vida e surtout de Chapman, nous ne l' [le mythe] avons relevé chez aucun autre poète. ${ }^{81}$

79 Vgl. dazu Angelo Poliziano, Miscellaneous poems. Ad Patrem, S. 155, Vv.16-20. Genannt bei Raymond Trousson, Le thème de Prométhée dans la littérature européenne, $\mathrm{Bd}$. 1, Genève 1976, S. 153 .

8o Rolfes, Die lateinische Poetik, S. 199. Es handelt sich nicht im strengen Sinne um einen „Diebstahl“, denn die Götter erlaubten die Überbringung des göttlichen Geschenks.

81 Trousson, Le thème de Prométhée, S. 134. 
In Vidas Poetik ist Prometheus noch nicht der kongeniale und anmassende Schöpfer, wie er es später, zum Beispiel bei Goethe, sein wird. Ebenso ist er nicht, wie bei Poliziano, selbst einer der vates. Aber Vidas Prometheus verbindet mit dem zivilisatorischen den dichterischen Aspekt und spricht der Dichtung denselben essenziellen kulturellen Wert wie dem Feuer zu.

\section{4 Überraschung und Staunen in der Literatur: Scacchia Ludus}

$\mathrm{Zu}$ den Werken, die im Zeitraum der Poetik entstanden sind, zählen die lateinischen (Lehr-)Dichtungen Scacchia Ludus ${ }^{82}$ und Bombyces. Erstere wurde über achtzigmal neu aufgelegt und unzählige Male übersetzt. ${ }^{83}$ Scacchia Ludus führt, mythologisch eingebettet, die Regeln des Schachspiels vor, und zwar indem das Schachbrett als lebendiges Kriegsfeld - angeführt von den jungen Göttern Phoebus und Merkur - inszeniert wird. ${ }^{84}$ Die Verlebendigung des Schachspiels ist dem Effekt der énargeia unterstellt: Erzählt wird in Bildern, die das Erzählte unmittelbar veranschaulichen.

Der klassische Stoff des Epos - der Krieg - wird als (Schau-)Spiel dargestellt. Bezüge an antike Vorbilder klingen an, insbesondere an die Batrachomyomachia ${ }^{85}$ des Pseudo-Homer oder die Ludus Troiae der Aeneis. ${ }^{86}$ Näher ist es an Letzteren, denn Scacchia Ludus entbehrt des parodistischen Charakters des pseudo-homerischen Epyllions und stellt - wie Vergil - die feierlich-rituelle Stimmung in den Vordergrund. Die Bewunderung der «mira[e] art[is]» Vergils (I, V. 167), die Vida in seiner Poetik dem Schüler

82 Originaltext und Übersetzungen zitiere ich aus: Marcus Hieronymus Vida, Schachspiel der Götter. Scacchia Ludus, eingeleitet und mit der Übersetzung von Johann Joseph Ignatius Hoffmann, herausgegeben von Walther Ludwig, Zürich / München 1979.

83 Johann Joseph Ignatius Hoffmann, Einleitung, in: Vida, Schachspiel der Götter, S. 5 .

84 Das Schachspiel hat in Europa seit dem 13. Jahrhundert im Zuge der «islamischen Expansion » Verbreitung gefunden und etablierte sich bald als eine der sieben « Tugenden der Ritter». Die « heute noch gültigen Regeln» wurden zu Beginn des 16. Jahrhunderts festgelegt, entstanden also wenige Jahre vor der Verfassung der Scacchia Ludus. Siehe dazu HoffMAnN, Einleitung, S. 5; ebenso https://de.wikipedia.org/wiki/Schach\#Geschichte (Stand April 2021).

85 Hoffmann, Einleitung, S. 9: «Das kleine Werk, das eine Schlacht zwischen Mäusen und Fröschen im Stil der Kampfszenen der Ilias darstellt und dafür auch den epischen Götterapparat heranzieht, war im fünfzehnten und sechzehnten Jahrhundert außerordentlich beliebt. »

Ebd., S. 8-9. 
mitzugeben versucht, ist in Scacchia Ludus durch den inhaltlichen, stilistischen, metrischen ${ }^{87}$ und atmosphärischen Anschluss literarisch gestaltet.

Während Vergil die Spiele in Erinnerung an den verstorbenen Anchises veranstalten lässt, wird das Schachspiel bei Vida als unterhaltendes Schauspiel an der Hochzeit von Oceanus und Tellus auf Geheiss des Bräutigams aufgeführt. Das literarische (Schach-)Spiel begleitet die Entstehung der Erde und der Menschheit und bildet den Übergang des Göttlichen zum Menschlichen.

Sowohl die Ludus Troiae als auch Vidas Schachspiel werden von Anfang an von einem staunenden Publikum verfolgt:

incedunt pueri pariterque ante ora parentum

frenatis lucent in equis, quos omnis euntis

Trinacriae mirata fremit Troiaeque iuventus. ${ }^{88}$ (Aen., V, Vv. 553-555)

Tum superis tacite secum mirantibus inquit:

$[\ldots]^{89}$ (V. 29)

Wird Vergil in De arte poetica als einziger Dichter gepriesen (I, Vv. 165-173), der die griechischen Götter zu erstaunen vermag, staunen ebendiese Götter in Scacchia Ludus über die Präsentation des Schachspiels.

Analog zu Vergil, der erzählt, wie das «Trojaspiel» nach Rom gelangte, leitet Scacchia Ludus mythologisch die Herkunft des Schachspiels in der lateinischen Kultur her. ${ }^{90}$ Der Autor wähnt sich als Erster, der sich dem Schachspiel literarisch annimmt (Vv. 5-6).

Der Anspruch, erster auf einem bestimmten Felde der Dichtung zu sein, war von den römischen Verfassern epischer Lehrgedichte regelmäßig erhoben worden. Die Art, wie Vida in seinem Prolog davon spricht, schließt sich zum Teil wörtlich an die Ausdrücke an, mit denen Lukrez für De rerum natura, Vergil für die Georgica und Manilius für die Astronomica diesen Anspruch geltend gemacht hatten, wodurch Vida deutlich die Reihe dieser Dichter fortsetzen und sein Werk auch als ein neues lateinisches Lehrgedicht gewürdigt wissen will.91

Der Erzähler inszeniert sich als jugendlicher Dichter und bittet die seriadischen Nymphen, ihm bisher unbestiegene Felsen («inaccessas rupes») und

87 Die epische Kleinform bedient sich klassisch des Hexameters.

88 Herein reiten die Knaben und bieten gleicherweise vor den Augen ihrer Eltern auf gezügelten Rossen ein strahlendes Bild; ihren Zug bestaunt und umjubelt Trinacrias und Troias ganze Jugend.

89 Als nun die Himmlischen sie [die Schachfelder] mit Staunen betrachten [...]

90 Hoffmann, Einleitung, S. 9.

91 Ebd., S. 9 . 
verborgene Pfade («secretum callem ») aufzuzeigen. Mit «glühendem Eifer » will er sich einen Weg bahnen, wo bisher keiner ist («[n]ulla via est»):

Dicite, Seriades Nymphae, certamina tanta

Carminibus prorsus vatum illibata priorum.

Nulla via est; tamen ire iuvat, quo me rapit ardor,

Inviaque audaci propero tentare iuventa.

Vos per inaccessas rupes et inhospita euntem

Saxa, Deae, regite, ac secretum ostendite callem. ${ }^{92}\left(\mathrm{Vv} \cdot 5^{-10}\right)$

Eine wörtlich analoge Stelle kennen wir aus De arte poetica (II, V. 7), allerdings werden dort nicht die seriadischen Nymphen, sondern in Anlehnung an Vergils Bucolica die Pieriden angerufen. ${ }^{93}$ Die Verortung des Gedichts innerhalb einer neuen lombardischen Mythologie prägt Vidas Dichtung und verleiht ihm Eigenständigkeit. Fiktionen dieser Art sind, wie wir in De arte poetica gesehen haben, nicht nur erlaubt, sondern erwünscht, denn sie erhöhen die Aufmerksamkeit der Leser und verleihen dem Erzählten ein originelles Profil (II, Vv. 315-316).

In den letzten beiden Zeilen von Scacchia Ludus (Vv. 657-658) bezeichnet sich der Erzähler in der dritten Person als Jüngling, dem die erzählte Geschichte von den Nymphen anvertraut wurde, als diese ihn an den heimischen Ufern des Serio singen hörten - er stilisiert sich als direkte Verbindung zu den Musen und präsentiert seinen Stoff als göttliche Überlieferung. Genauso wie in Bombyces ${ }^{94}$ schafft Vida in Scacchia Ludus eine «antikisierende Ursprungslegende »:95 So habe die Seriade Scacchis das Schachspiel nach Italien gebracht, nachdem sie es als Wiedergutmachung von Merkur geschenkt und gelehrt bekommen habe (Vv. 646-654). Diese Sage bildet den Rahmen des Gedichts, in dessen Zentrum das lebendige Spiel steht, das Oceanus an seinem Hochzeitsfest den himmlischen Gästen zur Unterhaltung bietet.

Der ambivalente Charakter des Kurzepos wird von Beginn an offenbar: Ein ernster und kriegerischer Epenstoff wird als feierliches (Schau-)Spiel an einer

92 Singt, seriadische Nymphen den Kampf um den lohnenden Lorbeer, / Nie noch besungen zuvor durch früherer Dichter Bemühen. / Öd' ist dieses Gebiet; doch treibt mich glühender Eifer / Mutig, nach Sitte der Jugend, den Weg mir beharrlich zu bahnen. / Lenket ihr Göttinnen mich auf nimmer bestiegene Felsen, / Zeiget zum Ziel den verborgenen Pfad, mich sicher geleitend.

93 PAPpe, Commentaire, S. 109, Fn. 6o.

94 Bombyces mythologisiert die cremonesische Seidenproduktion.

95 Hoffmann, Einleitung, S. 7. An dieser Stelle findet sich eine hervorragende Nacherzählung des Mythos rund um Serius und Phaëtusa, der den Rahmen von Bombyces bildet. 
Hochzeit inszeniert. Der Erzähler erläutert die Beschaffenheit und die Aufstellung der künstlichen, aber lebendig scheinenden Figuren (Vv. 37-39), bevor Oceanus die Regeln des Spiels - abwechselnd in Kriegs- und Spielrhetorik darlegt. Daraufhin bestimmt Jupiter seine zwei Söhne Phoebus und Merkur beide in «jugendlich blühender Anmut » (Vv. 176-185) - als die beiden Spieler. Die Episode ist frei erfunden, sie findet sich nicht in den Überlieferungen der antiken Mythologie.

Dass Jupiter übergeordnet das Kriegsspiel anleitet, zeigt eine gewisse Parallele zur Rolle, die ihm in De arte poetica zuteil wird: Der Göttervater war es, der die ersten Orakelgesänge sprach und der nach und nach die Überlieferung der göttlichen Gesänge an die Menschen anordnete. Diese ursprünglichen Gesänge wurden als « laudes heroum » (I, V.544) bei festlichen Aktivitäten von den Menschen gesungen. Ein ebensolcher Götter- und Heldengesang wird hier intradiegetisch von Jupiter als Spiel initiiert.

Nach anfänglichem Zögern ereifern die jungen Götter sich mehr und mehr für das Kriegsspiel, in Kampfeslust denken sie sich listige Fallen aus, um den König des Gegners zu töten. Mit sprechenden Vergleichen wird die Stimmung der Spieler veranschaulicht, hier von Phoebus:

Sicut ubi dextrum taurus certamine cornu

Amisit, dum se adverso fert pectore in hostem,

Saevior in pugnam ruit armos sanguine et alte

Colla animosa lavans: gemitu omnis silva remugit. ${ }^{96}$ (Vv. 256-259)

Der Vergleich mit dem «streitenden Stier» ist auf der einen Seite äusserst anschaulich, auf der anderen Seite betont er die kriegerische Seite eines Gottes, der uns eher als der «[g]länzende» und liebliche Gott der Weissagung, der Musik und der Dichtung bekannt ist. ${ }^{97}$ Allerdings gibt es in der Etymologie zu den Namen „Apollon“ und „Phoibos“ seit den Griechen Deutungsversuche, die Apollon mit dem Vernichtenden, Phoibos mit dem Furchtbaren assoziieren ${ }^{98}$ Vida hebt diese weniger geläufigen Aspekte hervor und erzielt damit jenen Überraschungseffekt, den er im zweiten Buch von De arte poetica einfordert.

In De arte poetica wird Apollon sowohl als mantischer Urvater der Dichtung als auch als Vorfahre Vergils gepriesen (I, Vv. 36, 88, 165). Zudem ist er Mentor für

96 Gleich wild streitendem Stier, der im Ringen beraubet des rechten / Hornes, entgegen sich stellet dem Feind zum heftigen Angriff, / Lechzend nach Kampf, den gewaltigen Hals, die gedrungenen Schultern / Badet im strömenden Blut: Dumpf schallt vom Gebrülle die Waldung.

97 Siehe dazu das Lemma « Apollon » in Der kleine Pauly, Bd. 1, S. 442-447.

98 Der kleine Pauly. Lexikon der Antike, Bd. 1, S. 442. 
junge Dichter, die von ungezügeltem Furor erfüllt sind. Seine Charakterisierung in Scacchia Ludus ergänzt jene aus De arte poetica, insbesondere bildet seine kriegerische und jugendliche Rolle eine originelle Herleitung dafür, Apollon als Gott des Epos und "Vater" Vergils zu etablieren. Aus anderer Warte könnte man aber auch sagen, Apollon werde in Scacchia Ludus abgewertet - denn nicht er dient dem Erzähler als Inspiration, sondern die norditalischen Nymphen. Der Erzähler beweist hier seinen spielerischen Umgang nicht nur mit seinen Quellen, sondern auch mit etablierten Figuren der griechischen Götter- und Figurenwelt. ${ }^{99}$

Das Bild des lieblichen Gottes wird erneut erschüttert, als Phoebus und Merkur beginnen, sich betrügerischer Methoden zu bedienen. Diese werden stets aufgedeckt und gerügt und schüren die gegenseitige Kampf- und Siegeslust umso mehr. Die beiden Götter erweisen sich mehr und mehr als Herrscherfiguren, ihre Rolle überlagert sich mit derjenigen des Königs im Spiel. Umgekehrt werden Götter und Herrscher zu Schachfiguren, was eine originelle Metapher für die Fatalität der antiken Mythologie auf der einen und die Abhängigkeiten politischer Herrscher auf der anderen Seite darstellt.

Doch Vida erweitert nicht nur die Figuren und deren Rollen, sondern auch das Schachspiel selbst: Der Ablauf und die Regeln werden auf überraschende Weise verlebendigt und die Schachfiguren werden zu Figuren mit menschlichen Absichten. So ersetzen die Könige ihre auf dem Schlachtplatz getöteten Damen ${ }^{100}$ - wenngleich «auch in beiden die frühere Liebe [unwandelbar bleibt] » (V. 451) - und nehmen je eine der Dienerinnen zur Frau, um die mächtige Position der Dame zurückzuerlangen (Vv. 411-417, 451-484). Ist dies ein dem Schachspiel fremdes Vorgehen, entspricht es durchaus der realen Praxis von Fürsten und Königen - ebenso auch demjenigen einzelner Götter.

Zusammengefasst lässt sich Scacchia Ludus als Aneinanderreihung verschiedener Überraschungseffekte beschreiben:

1. Das Thema des Schachspiels als Inhalt eines Kleinepos wird vom Erzähler als neues, bisher unbekanntes Thema angepriesen. Das Neue und Überraschende wird dadurch als explizites Ziel in die Lesererwartung eingefügt.

2. Die Götter sind überrascht über die Ankündigung des Schach-Schau-Spiels.

3. Den Lesern wird eine unbekannte Seite bekannter Götter präsentiert: Die zentralen Götter Phoebus und Merkur befinden sich im zarten Jugendalter, über jene Attribute und Taten, mit denen sie später bekannt werden,

99 Vgl. dazu II, Vv. 546-548.

100 Für die Königin verwendet Vida denselben Wortschatz, wie Vergil ihn für die kriegerische Camilla verwendet hat: regina, virgo und Amazon. Siehe Hoffmann, Einleitung, S. 10-11. 
verfügen sie noch nicht. Insbesondere werden sie uns als Spieler und Figuren des Schachspiels präsentiert, was ein neues Bild von ihnen schafft.

4. Das Schachspiel verlebendigt sich mehr und mehr als reales Kriegsfeld, das den Kampf zwischen zwei Königen demonstriert. Mit dem Spiel werden so nicht nur die Regeln des Schachs, sondern insbesondere auch die List- und Betrugsstrategien von Herrschern im Krieg vorgeführt und versinnbildlicht.

5. Letzter grosser Überraschungseffekt ist der Sieg Merkurs über Apollon. Nicht der Gott der Künste und der Weisheit, sondern der Götterbote gewinnt das Duell, was eine poetologische Leseweise des Lehrgedichts auf den ersten Blick erschwert.

Die Niederlage im (Kriegs-)Spiel wird zu einem Attribut Apollons, woraus verschiedene Interpretationen folgen können. Eine wäre die folgende: Der Krieg ist das Terrain des Mars, nicht des Dichtergottes. So taugt der kriegerische Stoff bei Vida nur als spielerisches Schauspiel, in den anderen Werken wird er nicht mehr aufgegriffen. An die Stelle des Krieges treten religiöse Stoffe, was sich in den geistlichen Texten und Briefen, insbesondere aber im späteren Hauptwerk - der Christias - manifestiert. Scacchia Ludus gibt so einen neuen Blick auf das Epos frei und nimmt die stoffliche Innovation, die Vida mit der Christias vollziehen wird, vorweg.

Das Neue und Überraschende, das bei den Lesern mit Vergnügen und Staunen aufgenommen wird, manifestiert sich auf allen Ebenen des Textes: auf jener der Gattung, des Stoffes, der Figuren sowie der Sprache, insbesondere der Sprachbilder. Vida bereitet in seinem berühmten Kleinepos vor, was er seinen Schülern in De arte poetica ans Herz legen wird:

$[\ldots]$ Tu nocte, dieque

Exiguum meditator, ubi sint omnia culta,

Et visenda novis iterumque, iterumque figuris. ${ }^{101}$ (II, Vv. 339-341)

\subsubsection{Exkurs: Das lebendige Schachspiel der Hypnerotomachia Poliphili}

Vida war nicht der Erste seiner Zeit, der das Schachspiel literarisch aufgegriffen hat. Ihm voraus ging die Beschreibung eines Schach-Schau-Spiels mit lebendigen Figuren in der Hypnerotomachia Poliphili - ob Vida diese kannte oder nicht, ist ungewiss, aufgrund der breiten Verbreitung der einflussreichen Traumerzählung aber durchaus denkbar.

$101[\ldots]$ Du, Tag und Nacht, / denke über etwas Unbdeutendes nach, von dem alles bekannt ist, / und betrachte es wieder und wieder, um neue Figuren zu kreieren. 
In der Hypnerotomachia bildet das Schachspiel den Abschluss des Besuchs im Palast der Königin Eleuterylida - diese ordnet das Spiel nach einem feierlichen «Gastschmaus » an. Hat bereits das prächtige Mahl Poliphilo «überwältigt » und «vor Verblüffung ohne Verstand» zurückgelassen, bietet das Schachspiel eine « noch größere[] Darbietung » $(H P, 119)$ :

Per laquale cosa ad maiore obstentatione uolendo la excelsa Regina oltra lantedicte cose dimonstrare lo excesso \& la superantia di luniverso in tutte excellente \& rarissime magnificentie, Sedendo ogniuno ad gli lochi sui, dopo il miraculo dil sumptuosamente conuiuare, Sencia protracta mora, ordinoe uno spectando ioco, digno non tanto di intuitione, ma di æterno memorato, che etiam fue una præstante Chorea, o uero Ballo, cum tale processo \& modo. $(H P, 119)^{102}$

Poliphilo lässt das Schachspiel als Teil seiner Traummythologie fungieren, wobei es nicht wie bei Vida als Kriegsspiel, sondern als prächtiger Tanzreigen aufgeführt wird. Die Figuren sind in silberne oder goldene Tücher gekleidet, sie bewegen sich zu Musik von «allermildester Harmonie und tönender Melodie» $(H P, 119)$, auf Geheiss des Königs sowie nach bestimmten - im Roman erläuterten - Regeln $(H P, 120)$. Wird eine Figur „besiegt“, wird sie gefangen genommen und mit einem Kuss vom Spielfeld verabschiedet. Das Spiel dauert so lange, bis « derjenige von Silber als Sieger verblieb; mit Heiterkeit, Verlustigung und Beifall $\gg(H P, 120)$. Das Spiel wird dreimal wiederholt, wobei die Musiker in der dritten Wiederholung das Taktmass erhöhen und der fröhliche Tanzreigen unmittelbar zu einem «Kampf», einem «Turnier » gerät $(H P, 121)$. Allerdings ist auch das dritte Spiel viel mehr feierlicher Tanz als Kampf, denn « dieser Vorgang ereignete sich solch gefällig und mit solcher Gelenkigkeit in einem Zuge, mit ihren tiefen Herabbeugungen und artigen Wirbeln und leichtfüßigen Sprüngen, mit reizend schönen Gesten»(ebd.). Poliphilo wird über das Schachspiel nicht der Macht der Könige, sondern der Macht der Musik gewahr:

102 Da die erhabene Königin zum Zwecke noch größerer Darbietung, über das Vorhergenannte hinaus, das Übermaß und die Hochherrlichkeit in der Gesamtheit aller herausragenden und allerseltensten Prachterscheinungen aufzeigen wollte, ordnete sie, während nach dem Wunder des aufwendigen Gastschmauses jeder noch an seinem Platz saß, ohne hingezogenem Aufschub, ein zu betrachtendes Spiel an, welches in bemerkenswerter Weise nicht nur des Anschauens würdig war, sonder auch des ewigen Gedenkens. Denn nunmehr gab es einen vortrefflichen Reigen, oder aber Tanz mit solcher Abfolge und Weise $[\ldots]$ 
io caldamente pensai che egli cum el suo canto le exercito del magno Macedonico ad reassumere larme uiolentasse, \& poscia reflectendo le uoce \& il tono, neglecte le arme tutti cessabondi prouocare. $(H P, 121)^{103}$

Das Schachspiel der Hypnerotomachia dient in erster Linie zur Veranschaulichung der Wirkung von Tanz und Musik, gleichzeitig ist es eine königliche Prachtdemonstration. Die Szene endet mit dem Sieg des goldenen Königs und lässt die Zuschauer in « äußerster Freude und größter Wonne » $(H P, 121)$ zurück.

Sind die Vorzeichen und die Atmosphäre der Schachspiel-Vorführung in den beiden Texten unterschiedlich, sind sie dennoch in entscheidenden Merkmalen gleich:Das Schachspiel wird als ungewohnte Seltenheit bezeichnet, über das die Zuschauer im Falle Vidas erstaunt, im Falle Colonnas erstaunt und in höchstem Masse erfreut sind. In beiden Texten dient das Spiel der Unterhaltung an einem festlichen Anlass, wobei es bei Vida eine zentrale Rolle erfährt, während es in der Hypnerotomachia vor allem von dekorativem Wert ist. Beide Schachszenen sind in einen originellen mythologischen Kontext eingebettet: Konstruiert Vida ein neues Setting mit fiktiv erweiterten Figuren der antiken Mythologie, schafft die Hypnerotomachia eine frei aus der Traumfantasie erfundene Erzählung. Bei beiden sind das Spiel und dessen Kontext Ausdruck der künstlerischen Freiheit, die Neues und Staunenswertes zur Unterhaltung der Leser vorbringt.

\subsection{Konklusion}

In De arte poetica entfalten sich die drei Themenbereiche - Didaktik, Inspirationslehre und Rhetorik (inventio, dispositio und elocutio) - in einem Rahmen des Staunens, wobei dieses je nach Bereich unterschiedlich typologisiert wird.

Für die Didaktik ist es essenziell, dass der Lehrer seinem Schüler die Bewunderung für und das Staunen über die Dichter und ihre Werke weiterzugeben vermag. Er erzielt dies durch einen konstanten Gestus der admiratio: zum einen in konkreten Äusserungen des Staunens, zum anderen durch die Schaffung innovativer, unerwarteter Mythen und Sprachbilder.

103 Aus dieser solchen Ursache begriff ich [...] wie er mit seinem Sange das Heer des Großen Makedoniers zum Wiederaufnehmen der Waffen zwang, und es, da er Stimme und Tonlage abwandelte, hervorrief, daß sie, die die Waffen alle liegenlassen, innehielten. 
Das Inspirationsmoment als göttlich-mystischer Zustand versetzt den Dichter in einen Zustand ausserhalb seiner selbst und lässt ihn Worte sagen, die nicht von ihm zu stammen scheinen. Erstaunlich ist diese Dichtung aber noch nicht; dazu gehört erst noch das dichterische Handwerk, das den Text in eine angemessene und wirkungsstarke Form bringt. Trotzdem verleiht der staunenswerte Ursprung der Dichtung eine Aura des Wunderbaren, die ihm auch nach gründlicher Überarbeitung weiterhin anhaftet.

Für die Wahl des Stoffes (inventio) bleibt der Text relativ allgemein, gibt aber zwei eingrenzende Vorgaben: Von den alten Griechen soll er in seinem Fundament abstammen und heroisch soll er sein. Auf dieser Basis kann die kreative inhaltliche und sprachliche Arbeit des Dichters aufsetzen. Als Techniken der dispositio, die die Aufmerksamkeit des Lesers erhöhen, werden das Neue, das Spannende, das Überraschende genauso wie die optimale Kombination aus Tradition und Innovation genannt. Ebenso bilden fiktive Einschübe ein zentrales Mittel, die Aufmerksamkeit zu halten oder gar zu steigern. Analog verhält es sich mit den Vorgaben zur elocutio: Ausserordentliche stilistische Effekte resultieren aus Momenten der Verfremdung sowie aus Neologismen. Insbesondere die Metapher mit ihrer Funktion, neue Bilder und Zusammenhänge zu schaffen, wird als Staunen erzeugendes Mittel hervorgehoben.

Obwohl nicht explizit als Poetik des Staunens formuliert, finden sich die rhetorischen Erläuterungen eingebettet in superlative Ausdrücke des Staunens gegenüber Vergils Werk und der Dichtung im Allgemeinen, wobei das Staunen sowohl den Ursprung wie auch das Ziel der Dichtung darstellt. Vida formuliert damit eine ausschliesslich wirkungsästhetische Idee des Staunens; es zählt nicht zu den produktionsästhetischen Mitteln von inventio, dispositio und elocutio, aber diese stehen implizit in seinem Dienst.

Wie die Silvae Polizianos oder der Actius von Pontano stellt auch De arte poetica die Dichtung in den Kontext einer mythologischen Ursprungslegende, die die Dichtung aus dem Staunen motiviert. Vida bezieht sich auf den Mythos des Prometheus, der Orpheus-Mythos bleibt unerwähnt. Das Konzept des Neuen - sei dies in Bezug auf den Stoff oder auf die Sprache - wird ähnlich wie bei Pontano stark betont und ist häufig an das Fiktive gekoppelt. Vida hebt dieses genauso wie seine Vorgänger als spezifische Gestaltungsmöglichkeit der Dichtung hervor.

Die Bildlichkeit und Lebendigkeit der Sprache, zentral für alle bisher untersuchten Autoren, werden insbesondere im Werk Scacchia Ludus vorgeführt, das - ähnlich wie in Lepidina - ein Hochzeitsschauspiel, eingebettet in eine neue, topographisch motivierte Mythologie, vorführt. Staunende Blicke der beiden Protagonisten bilden in Lepidina das Leitmotiv, während die Blicke der staunenden Götter in Scacchia Ludus den Auftakt zu einer Erzählung 
markieren, die aus den Spielzügen heraus motiviert ist. Staunende Blicke seitens der Protagonisten sind bei Vida weniger häufig als bei Poliziano, Pontano oder Colonna; die Ausserordentlichkeit des Erzählten wird bevorzugt mit anderen Mitteln markiert, zum Beispiel dem Hervorheben des Neuen oder aber mit unerwarteten Metaphern und fiktiven Erweiterungen bekannter Inhalte und Figuren.

Während Poliziano seine Texte vorwiegend dem Lob der Medici gewidmet hat, sehen Pontano und Vida ihre Dichtung als Stärkung, teilweise gar als wirkungsstarken Ersatz einer bröckelnden politischen Macht. Pontano widmet seine Texte der aragonischen Königsfamilie. An die Stelle der politischen setzt er eine kulturelle Macht und definiert Kampanien zum einen als Ort der griechischen Mythologie - beispielsweise durch die geographische Verortung der herkuleischen Taten -, zum anderen als poetische Wirkkraft, in die sich die vulkanische Gegend durch eine neue Mythologie transformiert. Ähnlich setzt Vida, der mit dem Tod Leo X. die Kräfte Italiens schwinden sah, die Dichtung an die Stelle politischer Kräfte. Leo X., die politische Leitfigur von De arte poetica, wird durch die poetische Leitfigur (Vergil) abgelöst. In Scacchia Ludus tritt das literarische (Schach-)Spiel an die Stelle des realen Kräftemessens zwischen den Herrschern. Die Ablösung der politischen durch die poetische Kraft zeigt sich vornehmlich darin, dass es nicht mehr die Herrscher sind, deren Stärke und Mut gelobt und bewundert werden, sondern die Dichtung.

Während Poliziano die Mittel der variatio und innovatio, Pontano zudem klangliche und metrische Mittel betont, führt Vida - wie Colonna - das poetische Gelingen auf die klassischen Konzepte der Harmonie, der Ausgeglichenheit und der Angemessenheit zurück, wobei Letzteres auch von Pontano bekräftigt wurde. Nie aber stehen diese Konzepte über dem Gebot des Neuen und Unerwarteten, sondern sind diesem - und damit auch dem Ziel des Staunens - nachgeordnet. Die Einbettung der Dichtung in das Staunen sowie die Hervorhebung des Neuen machen Vida zu einem Poeten, der viel eher in die Folge von Pontano denn in die Rolle des Vorreiters klassischaristotelischer Poetiker passt. Dafür unterstreicht Vida in seiner Poetik, aber auch in Scacchia Ludus die kreative Lust und poetische Freiheit zu sehr, zudem ist seine Dichtung nicht zweckgebunden in einem moralisch-ethischen oder politischen Sinne. 